Insight, part of a Special Feature on Resilience and Vulnerability of Arid and Semi-Arid Social Ecological Systems

\title{
Of Models and Meanings: Cultural Resilience in Social-Ecological Systems
}

\author{
Todd A. Crane $^{1}$
}

\begin{abstract}
Modeling has emerged as a key technology in analysis of social-ecological systems. However, the tendency for modeling to focus on the mechanistic materiality of biophysical systems obscures the diversity of performative social behaviors and normative cultural positions of actors within the modeled system. The fact that changes in the biophysical system can be culturally constructed in different ways means that the perception and pursuit of adaptive pathways can be highly variable. Furthermore, the adoption of biophysically resilient livelihoods can occur under conditions that are subjectively experienced as the radical transformation of cultural systems. The objectives of this work are to: (1) highlight the importance of understanding the place of culture within social-ecological systems, (2) explore the tensions between empirical and normative positions in the analysis of social-ecological resilience, and (3) suggest how empirical modeling of social-ecological systems can synergistically interact with normative aspects of livelihoods and lifeways.
\end{abstract}

Key Words: adaptation; agropastoralism; climate change; Mali; modeling; resilience

\section{PROLOGUE}

Researcher: What is the cause of soil fertility decline in central Mali?

Marka agropastoralist: There are not enough cattle, and so not enough manure for the fields.

Researcher: What is the cause of soil fertility decline in central Mali?

Fulani agropastoralist: There are too many fields for the number of cattle.

Both the Marka and Fulani agropastoralists are describing the same phenomenon: a causal relationship in resource degradation within an agropastoral ecological system. By agreeing that there is an imbalance in the relative proportion of animal manure and cultivated space, they appear to be operating with the same conceptual model and analysis of the biophysical system. However, despite this semblance of agreement, they frame soil-fertility decline in fundamentally different terms; ones that emphasize not the only objective materiality of the system, but also their normative positions in relation to it. The Marka agropastoralist privileges the place of agriculture in the system, taking the number and size of fields as a constant, treating the proper number of cattle as a function of agricultural needs. The Fulani agropastoralist privileges the place of pastoralism, taking the number of cattle as the constant, and treating appropriate agricultural space as a function of animal (manure) availability. These positions stem from individuals' different institutionalized livelihood practices and normative values, that in this case correlate with systems of cultural identity. Starting with the premise that cultural systems are important parts of broader social-ecological systems, this work explores the place of cultural change within the context of long-term socialecological resilience.

\section{INTRODUCTION}

The extended severe droughts in the West African Sahel from the late 1960s-1980s, along with the overall relatively low annual average rainfall in the following decades, have effectively reset the climatic and ecological baselines in the region 
(Nicholson 2005, Bell and Lamb 2006). In socialecological terms, the most obvious immediate effect of the droughts was the famine induced by shortterm failure of agricultural and pastoral production. The devastation of the food system required a large portion of the population of the Sahel to live on imported food aid for several years (Batterbury and Warren 2001). Although the short-term effects were massive and well documented, the long-term effects are still unfolding to this day, with implications for the resilience of the Sahelian social-ecological system (Turner 1999, Vedeld 2000, Mortimore and Adams 2001, Dietz et al. 2004).

Rather than discussing resilience in terms of socialecological responses to annual droughts at the household or community level, which has been done before (Roncoli et al. 2001, Eriksen et al. 2005, Smucker and Wisner 2008), here, I examine of longterm resilience as a culturally defined experience, exploring the synergies and tensions between resilience as an analytical scientific lens and resilience as a "normative" cultural process. Note that "normative" is used to connote socially defined and held values and ideals regarding desirability or propriety of a circumstance or practice, rather than the objective empirical conditions themselves. Collectivity is a key aspect of this use of "normative" and distinguishes it from "subjective," which emphasizes individual experience and positionality.

The following questions will be addressed: What is the place of culture in a social-ecological system? How can normative, culturally bound positions be constructively articulated with empirical analyses of social-ecological resilience? Is it possible for the ecological and material components of a system to be resilient, while at the same time a cultural group within it is pushed over a threshold to a new state in which the most valued practices and beliefs become untenable, irrevocably transforming the culture itself? Do such transformations even matter?

Despite having made great strides in theorizing the integrated nature of human and ecological systems, much of the literature on resilience in socialecological systems implicitly privileges the material, both in terms of ecosystem functions and human-livelihood outcomes. The social components of vulnerability and resilience are most often construed in reference to how technological and institutional practices relate to material, biophysical, and socioeconomic outcomes such as ecosystem functions and livelihood security (Bebbington 1999, Scoones and Wolmer 2003, Fraser 2007). The emphasis on biophysical outcomes is understandable and, indeed, justifiable as biophysical systems are obviously fundamental to human well-being. There is also ample literature that acknowledges the validity of normative cultural valuation of landscapes, natural resources, and livelihood practices (Watson et al. 2003, Xu et al. 2005, Bottom et al. 2009), as well as the "social limitations of adaptations" (Adger et al. 2009). However, there is little that explores the relationships between empirical biophysical models and normative cultural models in ways that are robust, synergistic, and practical, although some movement is being made in that direction (Berkes and Jolly 2002, Stepp et al. 2003, Jansen 2009, Meinke et al. 2009).

The concurrent rise of decentralized governance and participatory research on natural resource management (Painter et al. 1994, Degnbol 1996, Benjaminsen 1997, Basset et al. 2007) in West Africa and elsewhere signifies a broader shift in thinking, one in which locals' perspectives on ecosystem management must be taken seriously in policy development and governance. This implicitly includes nontechnical, normative positions, in addition to technical knowledge. The inclusion of normative positions is particularly important in landscapes where various stakeholder groups have substantially divergent institutional structures, values, and visions for further development efforts (Frame 2008, Crane 2009, Jacobson and Stephens 2009). In semi-arid ecosystems, the technical challenges in the development of resilient agroecosystems are considerable. However, these cannot be separated from the various stakeholders' different normative positions in relation to natural resources and quality of life.

Acknowledging the legitimacy and importance of actors' positions and experiences within socialecological systems, I propose to define "cultural resilience" as the ability to maintain livelihoods that satisfy both material and moral (normative) needs in the face of major stresses and shocks; environmental, political, economic, or otherwise. This definition respects the integrity of subjective normative experience, recognizing that people's lives mean something to them, while also accommodating changes in behaviors, values, and social institutions that are inherent in cultural dynamism. Following from this, a lack of cultural 
resilience can lead to "cultural transformation." Thus, cultural transformation will be seen when shocks occur that cause ruptures or disjunctures in the connections between the social institutions, normative values, and the practices of day-to-day life. Such ruptures will inevitably be resolved somehow or another, but not necessarily smoothly or without damaging social upheavals.

Durkheim referred to the experience of holding cultural norms that are not able to be met because of new, usually degraded, material conditions, as "anomic declassification" (Lockwood 1992), a circumstance characterized by destabilization of social order under which unpredictable social upheaval can be expected and through which new social orders can arise. This closely parallels contemporary resilience concepts (Folke 2006). In ecological systems, a severe shock stimulates a "release" phase, which can be expected to be accompanied by violent discharges of energy and temporarily increased entropy. The same sorts of processes can occur within cultural systems, where shocks can stimulate disjunctures between normative values and material practices, creating a sort of cultural "release" process, through which there is relatively rapid change in system organization. In the contexts of cultural transformations, these "release" phases are generally times of tension or conflict for individuals and communities. As in ecosystems, such disruptions may lead to a new stable state of cultural practice (normative and/or material) that is substantially different than the original, and from which it may difficult to return to previous practices and norms even when circumstances change. Accepting that cultural systems, including normative values, are aspects of ecological systems, the challenge is then how to approach the integrated analysis both in one frame of reference?

Here, I propose steps toward the integration of empirical biophysical analysis and normative cultural analyses. This is intended to act as a complementary counterpoint to the other papers in this special issue of Ecology and Society. The methodology employed by most of the papers in this collection has been to construct conceptual models of dryland social-ecological systems and their transformations to better analyze the factors that contribute to vulnerability and resilience. This approach foregrounds external analysis of empirical phenomenon, including behavioral, institutional, and ecological components. My approach turns that of the others' on its head, in an effort to understand a system and its transformations from the perspectives of various actors whose lives and livelihoods are implied in social-ecological models. This approach acknowledges people's empirical, social-ecological behaviors, while simultaneously addressing the values and meanings through which they interpret those behaviors and systems. Using a qualitative case study from central Mali, vulnerability and resilience will be analyzed through two normative cultural lenses in the same landscape, highlighting how important data can be lost when social constructions of meaning are not integrated with materialist analysis of adaptive social-ecological processes. By taking this approach, I seek to explore opportunities for bridging and intertwining materiality and social construction in resilience research and adaptation science (Nelson et al 2007).

It is important to emphasize that this is not an argument against conceptualizing resilience as a function of biophysical and socioeconomic systems, but an argument in favor of coupling that approach with an analysis of resilience in cultural systems, as defined by the people living within them. Adger et al. point out that discussing systems transformations in biophysical and economic terms is important, but "...such analyses, framed in terms of utilitarian metrics, frequently fail to recognize that the experienced worlds of individuals and communities are bound up in local places and that the physical changes will have profound cultural and symbolic impacts" (2009:347).

Phrased another way, external analyses of a socialecological system tend to construe it solely as a mechanistic web of interlinking actions and outcomes. Although this may be empirically accurate, it is likewise incomplete. In internal analyses of the same social-ecological system, one conducted in the minds and communities of people who live within them, the web of actions and outcomes is equally a web of interlinking socially constructed meanings and normative values that are intimately interconnected with the material behaviors, social institutions, and environmental outcomes.

The tension between these two positions is captured in old anthropological concepts of "etic" and "emic" approaches to research. In brief, in an etic analysis of a system, behavior or belief seeks to frame the study in terms that are explicitly external to the 
subject being analyzed. In etic approaches, the terms of analysis may not have any particular meaning to the subject of study. Conversely, emic analysis of a system, behavior, or belief seeks to understand the logic and experience of people who are themselves within the system, engaging in the behaviors or holding the beliefs. Etic analysis is typically associated with behavioral or materialist research approaches, such as human ecology or political economy, whereas emic analysis is more associated with cognitive or social-constructivist research approaches, such as belief systems and identity. Much ink has been spilled debating the relative merits of each research approach over the other (for a classic, if polemic, discussion of etic/emic distinctions, see Harris 1976). However, this work starts from the premise that the more interesting challenge is to explore the relationships between collective cultural experiences and meanings (emic) and external analysis of behavioral practice (etic) in the context of adaptation to environmental variability and change. Social institutions of livelihood practice provide useful analytical focal points in pursuit of this goal because they effectively bind together the materialities of technological and ecological processes with ideological systems of meaning and collective identity.

Although there is no question that material, behavioral practices are key components of socialecological systems, normative and nonmaterial components of culture are likewise important for a variety of reasons. First, and most simply, biocultural diversity, which includes languages, values, and belief systems, is valuable in humanistic terms because it represents the range and richness of adaptive variation in human cultures (Maffi 2005, Cocks 2006). Secondly, culturally instilled values form the cognitive framework of lived experience, the lens through which events and relationships are evaluated and given meaning. Thirdly, and most importantly, whereas socially constructed meanings may not seem likely to directly affect soil fertility, climate change, or food security, they do create the frameworks through which potential adaptive pathways, which is to say alternative material behaviors, are analyzed, evaluated, and prioritized (Rappaport 1979, Nazarea-Sandoval 1995, Roncoli et al. 2009).

Such cultural ideologies, along with the social institutions that perpetuate and reproduce them, not only act as mechanisms of path dependency in adaptive processes, but they also form the cognitive and institutional frameworks through which resilience, or lack thereof, is experienced and socially defined (O'Brien 2009). In a research and development milieu that increasingly recognizes the importance and value of participatory governance, local self-determination and community-based natural resource management, social constructions of meaning regarding livelihood practices and system change must be taken seriously, particularly in cases where there is substantial divergence in stakeholders' political and ideological positions regarding landscape management. Such normative positions represent the points from which social groups will analyze empirical models and negotiate toward their desired goals in the politics of land use and natural resource management.

\section{RESEARCH SITE}

The Commune of Madiama is situated at the edge of the Bani River and its eastern floodplains, a unique geographical intersection on the southwest corner of the Niger River Inland Delta. The terrain is extremely flat and marked by sandy soils with occasional rock outcroppings on the eastern edge of the commune, where the gravelly Dogon Plateau begins to rise gradually to the east of the southern Inland Delta. The Commune of Madiama straddles the border of the upland-floodplain divide, giving its residents access to both river floodplain and rainfed agriculture. Average annual rainfall for the area is approximately $500 \mathrm{~mm}$, with the high interannual variability and patchiness characteristic of the Sahel (Badini and Dioni 2005).

The Commune of Madiama has 12 villages with approximately 10,000 total inhabitants. Although there is ethnic diversity within the commune, villages are mostly ethnically homogenous because of historical settlement patterns. The Marka ethnicity, often known as Sarakolé elsewhere, dominates the commune, with ethnic Bambara and Fulani minorities. Historically in central Mali, there had been sharp ethnic divisions in the human ecology. Most importantly for the purposes at hand, Fulani $\dagger$ have historically been transhumant cattle herders, whereas Marka, along with several other ethnicities, have been farmers.

From a social-ecological perspective, this organization of human ecology represents more than just a division of labor; it represents a strong correspondence among ecological niches of 
livelihood practice, technical knowledge systems, forms of social organization, and ethnic identities, all integrating into a single landscape-level system. However, the characterization as a system, should not be taken to indicate universal consensus among actors in the constitution of that system. Contestation over natural resource management regimes in the region has a deep history, takes many forms, and continues to this day (Cissé 1985, Moore 2005). Conflicts between farmers and herders relating to competing uses of land and water resources are increasingly acute (Moseley 2001, Turner 2004, Moritz 2006, Benjaminsen and Bubacar 2009).

The livelihood strategies of Marka and Fulani residents of Madiama fall on a spectrum of agropastoralism. The breadth within that spectrum is great and there is a range of diversity within each group, but there are also markedly patterned differences. Marka residents typically farm both subsistence crops (millet, sorghum, rice, cowpeas) and cash crops (watermelon, okra, calabash, rice) in large fields. Given increasing land pressure, fallowing is rarely practiced and farmers rely on the application of manure for soil fertility. Women often have small garden plots where they grow vegetables for cash or for household consumption. Livestock ownership ranges from zero in the case of the poorest households, to investment herds of 100 or more cows. Although the range is great, the average household ownership of livestock in the village of Madiama is estimated at two cows (draft oxen) and 1.6 small ruminants (Ballo and Ouattara 2005).

On the other hand, Fulani in the Commune of Madiama cultivate only subsistence crops (millet, sorghum, cowpeas, and a little rice) in relatively small fields, but have much higher rate of livestock ownership. For instance, the average resident of the largest Fulani village, Nerekoro, is estimated to own 31.5 cows and 13 small ruminants (Ballo and Ouattara 2005). (However, note that given ubiquitous hiding of cattle ownership for the purposes of tax evasion, these numbers are likely to be lower than the true figures.) Some official residents of Nerekoro reside in the village yearround, but others practice an annual transhumance, following herds from the eastern highlands in the rainy season down to the pastures in the Niger River Inland Delta in the dry season, passing through the village just twice a year. Fulani do not farm cash crops, and Fulani women do not work in fields or gardens at all, instead relying on sales of milk, butter, and handicrafts for cash income.

\section{METHODS}

The research presented here was part of a larger multidisciplinary research program, the Sustainable Agriculture and Natural Resource Management Collaborative Research Support Program (SANREMCRSP), funded by the United States Agency for International Development (USAID). The objective of SANREM was to develop an integrated method for participatory rural development that addresses both technical and institutional factors through a more bottom-up approach. The project involved a wide range of researchers from both the biophysical and social sciences. Details about the variety of biophysical and socioeconomic research conducted by the project team can be found in Moore (2005). Although SANREM's work was not explicitly framed in terms of understanding vulnerability and resilience, the focus on sustainability and improving adaptive capacity is implicitly oriented toward building resilient social-ecological systems in the face of environmental variability and increasing human demands on local natural resources.

The aspect of SANREM presented here draws from a comparative study of Marka and Fulani knowledge systems regarding soil and land management in the context of changing environmental and political circumstances, namely drought and decentralization. Unlike many local knowledge studies, which focus exclusively on technical knowledge of particular resources, this research intentionally elaborated the ways that technical knowledge is embedded in social institutions and normative aspects of livelihood behaviors, including constructions of ethnic identity through livelihood practices, as well as political positions on contestations over natural resource management. In taking this approach, knowledge is treated less as a static and disembodied thing in and of itself, and more as a dynamic and performative element that is situated in, and mutually constitutive with, broader cultural practices (Richards 1989, Niemeijer and Mazzucato 2003, WinklerPrins and Sandor 2003).

The research presented here was conducted over the course of three trips to Mali between summer 2001 and spring 2005, totaling 17 months in the field. 
Data are drawn from multiple methods, including key informant interviews, local history interviews focusing particularly on technological and ecological change, and informal discussions with residents of the Commune of Madiama. Furthermore, a formal ethnoecological survey was conducted with a random sample of 40 Fulani households from three villages and 40 Marka households from three villages, rendering a final participation of 26 and 38 households, respectively. (Fulani participation was low for two reasons: several households of "residents" were away on transhumance, and there was a high refusal rate, based on a strong disinclination to be in contact with any official or research processes.) The ethnoecological survey incorporated questions about technical ecological and management knowledge, social (especially interethnic) relations vis-à-vis natural resource management issues, and subjective experience of technical and institutional adaptive processes.

Whereas a systems resilience approach takes an analytical vantage point from outside a system, the approach taken here aims to extrapolate the cultural logics employed by people who operate within a system. Participant observation was an essential method for properly contextualizing and analyzing the material, institutional, and normative processes which form locals' experiential and analytical framework. Having lived in the Commune of Madiama for the entire course of my fieldwork, I participated in day-to-day and seasonal livelihood practices of both farmers and herders, I attended official natural resource management meetings at local and regional levels, and observed the locals' interactions with my research colleagues as well as the technical experiments. Just as the dynamic models in this issue were produced through "expert interviews" with the researchers themselves, the qualitative characterizations of environmental change, livelihood transformations, and senses of identity and valuation represent distillations of the myriad individuals and observations that constituted the research project.

\section{HISTORY, LIVELIHOOD CHANGE, AND CULTURAL RESILIENCE}

Applying a resilience perspective to cultural systems requires an understanding of how those cultural systems have developed over time, with particular attention to the social institutions around which the cultural identities are organized; in this case, livelihood practices. In any analysis that presumes to examine a "system," defining the boundaries of the system of reference is an important step. Recognizing that such boundaries are always artificial to some degree, for the purposes of this case, I am considering the system at the landscape level, incorporating both biophysical and social components (inclusive of behavior, organization, and ideology). From the social side, although the Marka and Fulani have lived in very close proximity to one another for long spans of time, it can be said that there is extremely limited overlap in their cultural systems. Their histories, identities, languages, and social institutions are distinct, and the social networks within ethnicities are far denser than the social networks between them. The practice of Islam is the single strongest connection between them, although each village maintains its own mosque.

Although the two groups could be independently analyzed as separate systems in terms of strictly social processes, in terms of landscape-level subsistence practices, what Painter et al. (1994) have called "action spaces," their activities overlap substantially. This overlap of action spaces has created some degree of close contact and mutual effect, if not necessarily social cooperation, between the farmers and herders throughout the area. This can sometimes include serious conflicts between farmers and herders, as well as competitive politics over land management (Moritz 2006, Turner 2006, Benjaminsen and Bubacar 2009, Benjaminsen et al. 2009, Moritz 2010). Thus, even though their social systems often have limited contact and are relatively separate, the ecological linkages between farmers and herders are substantial, which justifies characterizing them as part of one social-ecological system.

As such, it is appropriate to consider the landscapelevel changes in the social-ecological system that have occurred in Sahel following the droughts of the 1970s and 1980s that devastated both farmers and pastoralists. As recovery has unfolded, the general trend has been toward the mixed production strategy of agropastorialism for both groups, gradually moving into each others' ecological niches while maintaining previous social and cultural boundaries. The separate pathways to recovery of the Marka farmers and the Fulani pastorialists were predicated on their previous social and material conditions. The differences and 
similarities between current Marka and Fulani practices, and their social construction of those production behaviors, stem from the particular historical pathways that have brought the two cultural groups to their contemporary condition as agropastoralists. Thus, although contemporarily seeming to fill the same subsistence niche in the social-ecological system as agropastorialist, the Markas' and Fulanis' own construction of differences between their two cultures and their conceptualization of their positions (niches) within the social-ecological system, can be seen in the ways they describe themselves, each other, and the respective social values they assign to certain subsistence behaviors in the regional socialecological system.

\section{Marka Agropastoralism}

The Marka of Madiama have arrived at their condition as agropastoralists through a particular historical pathway that has affected the cultural experience of social-ecological resilience. According to local oral histories (which include living memory), up until the 1940s, the Marka of Madiama were traders and farmers, focusing primarily on rice agriculture in the floodplains of the nearby Bani River. Animal traction and animal-drawn carts did not exist in the area, and all agricultural labor at that time was done manually. The Marka did not keep cattle, and the only herding in the area was done by neighboring Fulanis. This began to change with the introduction of the ox-drawn plow in the late 1940s by the French colonial government, as described by an elder in the village of Promanii:

The plow came here, the first time I saw a plow was with the Canton Chief, sometime in the 40s. They were given to the Canton Chief and the village chiefs, and they were obliged to cultivate with them. Someone came to teach people how to use them. He was named Bokar. Starting from the 60s until now, there has gotten to be a lot of them. I got my first in 1959. I was among the first in the village, there may have been five or six others, but I paid for mine myself.

The introduction of the plow into the agricultural system was explicitly intended to increase food production in the region, but because plows need traction, it incidentally required that farmers integrate draft animals into their household livelihood portfolios. Consequently, the spread of the plow in the late $20^{\text {th }}$ century opened the door to Marka cattle ownership, as had occurred throughout West Africa and other parts of the world at other times (Fraser 2007). Later, exogenous development projects in the area have been oriented toward improving farmers' livelihoods though diversification and increasing market integration, which has further promoted the place of stock herding in the Marka livelihood portfolio. Since the 1980s, the UN, World Bank, and USAID, among others, have promoted the ownership of horse and donkey carts, necessitating the keeping of equines. The acquisition of carts and equines has also occurred privately through international development projects seeking to improve rural economic productivity through increasing farmers' ability to get produce to markets.

Throughout the last 25 years of increasing market integration, much of the profits from commercial agricultural sales have been invested in goats and sheep, in addition to draft animals. Small ruminants are seen as good investments because they multiply quickly and can be sold easily to cover sudden, small expenses. Their manure is also highly valued as a powerful input for soil-fertility maintenance, which is becoming increasingly important as pressure on land increases and fallowing is no longer practiced (Crane 2002, Crane and Traoré 2005). Because small ruminants are intensively managed and kept in pens in household compounds, their manure has come to be managed as an important resource, which is gathered and spread in fields prior to the agricultural season.

The overarching theme in the rise of Marka agropastoralism in this area, as characterized by the farmers themselves, is that increasing fortunes have led to the adoption of cattle keeping, which has in turn increased fortunes enough to invest in other livestock. Over the last few decades, animals have become a key capital component of the agricultural production system, in terms of traction, access to markets, and soil-fertility maintenance. The wealthiest of Madiama's farmers even own large investment herds, which are managed by hired Fulani herders far from the area. In short, cattle have been integrated into livelihoods as a subsidiary or supplementary component of a fundamentally agricultural livelihood practice.

Despite the rising prevalence and desirability of cattle ownership, agricultural production has 
remained the central institution around which social organization hinges and the Marka cultural identity as farmers has remained firm. Marka continue to self-identify as farmers, and livestock keeping carries the positive connotation of a progressive and prosperous (plow-equipped) farmer. For the Marka agropastoralists, the increased integration of animal husbandry in their livelihood portfolios is primarily an indicator of their success as farmers.

Although the technical transformations of the Marka agroecological system have precipitated subtle changes in labor organization, household economies, and land management, none of this has crossed over any thresholds which are emically characterized as resetting their cultural system to a new baseline state. Despite increasing cattle ownership, taking animals out to pasture is not done by household labor. Instead, the actual management of livestock herds is done by hired Fulani herders. Although the ecological changes caused by significantly reduced annual average rainfall since the 1970s have transformed once seasonal floodplains to rain-fed millet and sorghum fields, and economic development has increased the role of livestock in livelihood strategies, agricultural production is still the central institution around which household and village life is organized, materially, socially, and symbolically.

\section{Fulani Agropastoralism}

The contemporary Fulani residents of the Commune of Madiama are also agropastoralists from a technical point of view, mixing herding and farming activities in their livelihood strategies. However, their practice of agropastoralism, as well as the historical trajectory by which they arrived at it, is entirely different than Markas'. Subsequently, agropastoralism has been integrated with their cultural system in ways that carry different social meanings and promote different behavioral responses. In central Mali, and across Sahelian West Africa, the Fulani have long been known as transhumant cattle herders. As a key aspect of the ecology of Sahelian pastoralism, transhumance has been a central institution in Fulani livelihoods, social organization, and ethnic identity across the entire region (De Bruijn and Van Dijk 2001, van Dijk et al. 2004). Paul Riesman, a noted ethnographer of Fulani in Burkina Faso, observed that: "The cattle embody the highest values in Fulani society...One of the kinds of men most admired among the Fulani is one who "loves cattle", (1974:159). Consequently, despite the hardships involved, transhumance is a culturally revered way of life and is a central social institution around which household and cultural practices have historically been organized.

Historically, transhumant Fulani pastoralists had two modes of interaction with agricultural producers. First, they would sell milk, butter, and occasionally cattle to buy grain, produce, cloth, and other household goods. Alternatively, some transhumant Fulani used to own slaves who lived in their own villages and engaged in agricultural production, a percentage of which would be taken by the Fulani owners. During this era, slavery was institutionalized among all ethnicities across West Africa. What was unique in the Fulani case was its social form in relation to transhumance. Slave villages were located along transhumance routes so that there would be contact between owners and their slaves at least twice a year: once as the herds descended into the delta, which coincides with harvest season, and once as the herds leave the delta, which coincides with planting season. It is only in this sense that Fulani could be said to have historically practiced mixed agropastoralism as a household economic strategy. Slavery was outlawed by the French colonial regime in the $19^{\text {th }}$ century, and again by the newly independent Malian government in 1960, but patronage relationships often continue between the households of former slaves and owners. Still, for the Fulani themselves, agriculture has been supplementary to pastoralism and, above all else, it was work to be done by slaves.

Efforts to sedentarize the transhumant Fulani of central Mali date back to the early $19^{\text {th }}$ century, when a theocratic Muslim Fulani kingdom, the Dina, arose in the Niger River Inland Delta region. This effort was primarily motivated by the desire to discourage nonIslamic religious practices, and was not generally very successful. The French colonial regime's attempt to sedentarize transhumant Fulani, to make them more governable and taxable, likewise met with little success (Bruijn and Dijk 1994). However, the ecological catastrophe of the prolonged droughts of the $1970 \mathrm{~s}$ and $80 \mathrm{~s}$ transformed Fulani society in ways that are still being felt. Their herds were decimated and, without cattle, there was no longer any reason for transhumance to continue. Furthermore, to survive the famine, people relied on food aid, which was delivered to people only in their official village of 
residence. These two factors together forced the sedentarization of previously transhumant herders. As the rains returned and food aid was withdrawn, the now cattleless herders were effectively forced to take up agriculture to feed themselves and their families. Notably, contemporary Fulani agriculture in the area tends to be very intensive in nature, and explicitly oriented toward subsistence crops. Cash crops are not grown. As one elder said, "We don't try to make money from our fields. We make money from our animals." Farming is done only to the degree that it is necessary for survival, and when possible, many Fulani in the Commune of Madiama hire day laborers, usually Bambaras, Markas, or Bobos (another ethnic group common in the area to the east of Madiama) to conduct manual labor for them in their fields.

The historical trajectory through which the Fulani in central Mali have become agropastoralists is one that involves decline in sociopolitical power, increasing impoverishment, decreasing ability to engage in culturally valued livelihood practices, and increasing need to engage in a livelihood practice that has been disparaged for centuries. Fulani practice agriculture only in as much as it is needed to fill in the economic gaps not covered by herding. The steep decline of transhumance, which resulted from a combination of environmental and political forces, and the increasing incorporation of agricultural practices into Fulani livelihoods, represents a significant shift in livelihood practices; practices that, according to their those who engage in them, do not satisfy culturally valued lifestyles.

From an etic point of view, it is tempting to simply look at the Fulanis' increased adoption of agriculture as an adaptive way of life; the most effective means of achieving food security under new conditions. However, the subjective and collective experience of agropastoralism is more ideologically loaded for the Fulani themselves. Becoming a farmer is not just a new mode of subsistence; it is a fall from relative prosperity to a life of what they experience as degrading manual labor. From the emic point of view, to personally, physically engage in cultivation is to debase oneself by doing work associated with other ethnicities, as well as the lowest class in Fulani society. The fact of being an agropastoralist is a sign of just how bad things have become (de Bruijn 1997). As such, even where agropastoralism may be technically adaptive - decreasing vulnerability to climate shocks and food insecurity-from within normative Fulani cultural logic, the increasing institutionalization of agropastoral practice represents a lack of resilience, and a fundamental transformation of the cultural system to a new and stable state that is characterized as less desirable.

\section{DISCUSSION}

The question remains as to whether or not the socialecological system described here is rightfully described as resilient. The answer depends on the analytical frame through which "social-ecological system" is viewed, which is at least partly a function of the social position of the analyzer. From an exogenous, technical point of view, the adoption of agropastoralism by both the Marka and Fulani represents a diversification of livelihood strategies in response to long-term environmental change. Livelihood sustainability literature indicates that diversification generally reduces vulnerability to climate shocks, as well as other forms of ecological and economic stochasticity (Ellis 1998, Scoones 2009).

The Marka and Fulani of Madiama have responded to the same climatic and ecological circumstances by moving toward an increasingly similar, diversified livelihood strategy. Marka adaptations to this new environment have not substantially altered the bases of their self-perception vis-à-vis livelihood strategies, which is to say their normatively defined place within the socialecological system. The Marka cultural system, including livelihood practices, social institutions, and identity markers, has largely maintained a state comparable to what existed before the droughts. Intensive animal husbandry has been integrated into household and community livelihood systems, although largely through reliance on hired Fulani herders. By most material measures, Marka livelihoods have vastly improved through the adoption of mixed farming, while simultaneously maintaining their agricultural practices and identities. In short, ecological change and diversified production have been integrated into existing forms of social organization without a fundamental transformation of the cultural system, as defined by those living within it, indicating cultural resilience in the face of environmental stressors.

Analyzed in its own terms, the Fulani cultural system, which retains a strong valuation of 
transhumant cattle herding as a central component of ethnic identity, has not been so resilient. By moving toward a more diversified livelihood strategy that increasingly relies on agriculture, sometimes as a supplement to pastoralism and sometimes as its replacement, the Fulani cultural system in Madiama is being radically transformed, flipping to a new stable state that is unlikely to flip back even if rains return to their previous levels. The rise of agriculture in Fulani cultural practice is a direct result of the diminution of transhumance, a defining Fulani social-ecological institution that is at least six centuries old. As the physical act of transhumance has become increasingly untenable for a greater and greater percent of the Fulani population, the social institutions and practices around transhumance are likewise diminishing, leaving the cultural valuation of herding unfulfilled. Even though agriculture is important in satisfying the material need of food security, it does not satisfy a cultural "need" and is experienced and socially constructed as a cultural degradation.

However, no cultural group or practice has ever been static or ahistorical. Like technical behaviors, normative frameworks are extremely flexible in the face of adversity, but such change is gradual and not without its costs. Over time, most likely generations, the exigencies of the changing biophysical system, combined with political pressure, may increasingly normalize sedentary agropastoralism for more and more Fulani in central Mali. In one sense, the sedentarization and agriculturalization of Fulani herders is evidence of institutions that have the ability to change and learn, adapting to new circumstances. However, it is simultaneously experienced and socially constructed as a process of cultural loss, because of Fulanis' inability to forge livelihoods in a way that maintain endogenously valued practices and institutions.

An external, and exclusively materialist, analysis may conclude that the adoption of sedentary, agricultural livelihoods is a clear sign of socialecological resilience. However, from an emic perspective, it represents a resetting of livelihood practices and institutions to an entirely new, and less satisfying, baseline. In this sense, it exemplifies lack of cultural resilience, or perhaps a form of livelihood resilience that is synonymous with cultural degradation, both in material terms and in normative terms. For example, it was common for Madiama Fulani to refer to Fulani communities elsewhere in southern Mali, who gave up pastoralism and their language in the $19^{\text {th }}$ century resulting from political pressure, including the threat of violence, as having lost their "Fulani-ness." Despite having Fulani surnames and lineages, the sedentarized, agrarian Fulani are not seen as "real" Fulani by those who maintain the practice, or at least the ideal, of transhumant pastoralism, indicating the centrality of the transhumance to cultural identity.

A close analysis of resilience as it is experienced in cultural context is not necessarily universally useful. In some contexts, adaptive changes in technical practices and institutional functions do not indicate fundamental transformations of cultural systems. In other cases, such changes may be experienced as nothing but improvements, as is occurring among the Marka agropastoralists. However, in the cases where fundamental transformations are taking place, an emic perspective on cultural resilience in the face of environmental change can help elaborate the connections between materiality of livelihoods and ecosystem functions on one side, and the ways that people and communities socially construct the meanings of their own lives and landscapes on the other.

How, then, can normative cultural positions can be integrated into our understanding of socialecological resilience? Given the prevalence of modeling in the analysis of ecological systems, some suggest that cultural values and practices can be integrated into systems models, inasmuch as they direct behavior in predictable ways. However, this approach belies the dynamism of human behavior and culture, reducing it to a mechanistic and linear function (Jansen 2009). What is lost in this is farmers' proactive, creative, and diverse responses to environmental stresses (or economic or political stresses for that matter), a phenomenon that is well documented in the local knowledge literature (Richards 1986, 1989, de Boef et al. 1993, Rhoades and Bebbington 1995). Furthermore, abstract emic meanings connected to livelihood practices or landscape characteristics are likewise lost. Although some social factors, such as land-tenure systems, may sometimes be broadly manageable in modeling, trying to incorporate entire cultural systems into social-ecological models risks reducing extremely complex webs of human values, practices, and social institutions into oversimplified, mechanistic processes, ultimately disempowering those actors who live within the modeled system. As such, the desirability and utility of doing so is 
dubious. Instead, it may be more effective to explore means of understanding how and where models can be used to inform cultural practices, supplementing land managers' existing experienced-based learning. This has the potential to empower users to proactively engage in dealing with cultural changes which accompany environmental change.

Modeling, from qualitative dynamic systems modeling (as found in this issue) to quantitative ecological and climatological modeling, has emerged as a key technology in characterizing and anticipating system functions as drivers of, and responses to, environmental change. The utility of such models is typically characterized in terms of providing more or better information to policy makers, usually in national government agencies or international development institutions. This approach effectively says that these actors and institutions have the right, and power, to make the normative decisions about adaptation goals and processes for a region, despite the fact that those actors or institutions do not necessarily make their livings in the landscapes described, nor will they be directly affected by the suggested changes.

However, farmers and herders are themselves also policy makers of a sort. Individually, they may influence relatively limited geographic domains, but collectively their coverage is substantial. In the case described here, a model of the biophysical system could help inform adaptive processes by acting as a boundary object (Star and Griesemer 1989) linking farmers, herders, politicians, and scientists as they consider potential new modes of land management and livelihoods. By engaging the relevant actors who make their livings in the landscape, such discussions have the potential to more effectively integrate both technical and normative positions relating to potential adaptation pathways. Even if extensive pastoralism is not found to be a tenable outcome for all who desire it, using a model as a tool for anticipating change within the system, it enables a greater degree of selfdetermination over the processes of cultural transformation that accompany ecological and livelihood change.

\section{CONCLUSION}

I have asked whether the enhancement of biophysical systems' resilience can simultaneously result in the decrease of cultural resilience from the perspectives of those who make their livelihoods within the biophysical system. Furthermore, I have asked how normative cultural frameworks can be better integrated into research and development efforts focused on adaptation and resilience to climate change and climate variability.

From a modeling perspective, a social-ecological system is a heuristic device, which can be conceptual or quantitative, and is constructed to help analyze the ways that multiple factors interact and result in specific outcomes. This reduction of complex interactions to mechanistic abstractions is useful, and perhaps even necessary, in developing recommendations for policy makers and identifying potential leverage points for technical or social innovations. However, from the perspective of people who make their living within it, a socialecological system is more than just a useful heuristic construct. It is the very material, social and symbolic landscape that contextualizes and constitutes their lived experiences. This is not to say they would not recognize empirical components and mechanisms in abstract models, but that those models would be evaluated from positions situated within the system; positions that implicitly include normative values vis-à-vis empirical phenomena.

Just as building resilience into social-ecological systems is not simply a technical question, the objective of bridging materialist and constructivist analysis of social-ecological resilience is not simply an academic exercise. The examination the relationship between resilience as a quality of ecological systems and resilience as an experience within subjective and collective cultural frameworks will be a key challenge in making models more meaningful and useful to people who live within modeled systems. Adaptation science, within which modeling features heavily, has been described as "solution-oriented scientific endeavor in the global agenda to facilitate adaptation actions," and as contributing to "changes in systems to increase their adaptive capacity and performance" (Meinke et al. 2009). Inasmuch as adaptations in the sphere of land and landscape management occur locally and regionally, farmers and herders themselves must be partners in adaptation science, including their 
normative positions. The emergent and challenging question then becomes when and how to incorporate society into models, rather than when and how to incorporate models into society.

Adaptive performance, as defined by farmers and herders themselves, is enacted and judged from positions situated within social-ecological systems (see also Crane, in press). Consequently, the integration of both their empirical knowledge and their normative perspectives is an essential process in solution-oriented science in support of socialecological resilience. Recognizing that normative perspectives are flexible, dynamic, and negotiable, their inclusion in discussions of adaptive processes and opportunities has the potential to contribute to cultural resilience in the context of system change. The integration of cultural institutions and values into analysis and discussion of social-ecological systems will help forge an adaption science that is salient, credible, and legitimate in the eyes of the rural land managers who are at the front lines of building resilient and adaptive systems in response to climate change. If the research and policy communities can proactively acknowledge and engage normative cultural positions (including their own) as important parts of social-ecological systems, resilience and adaptation research can provide space for giving farmers and herders greater ownership over processes of cultural change that will inevitably be a part of adaptation to climate change.

\section{EPILOGUE}

Researcher: How should land-use conflicts between farmers and herders be dealt with?

Marka agropastoralist: Cattle problems should be dealt with by the village chiefs and the counselors. [Regional-level] administrative authorities should stay out of it.

Researcher: How should land use conflicts between farmers and herders be dealt with?

Fulani agropastoralist: The [regional-level] administrative authorities must involve themselves to open the cattle trails that are planted over by fields.

Why do cultural transformations matter in resilience and adaptation? From a humanistic point of view, they matter simply because people's quality of life as lived experience is something worth caring about and cultural diversity is in and of itself something to be valued.

However, there are also more practical systemic considerations as well. The above interactions illustrate that different cultural norms and practices can translate into divergent positions on how to move forward with adaptation in land management. In both cases, not only is the cause of the problem placed squarely on the "other," but the pathways toward solutions are substantively different. Circumstances have increasingly pressed the Marka and Fulani of Madiama toward convergent adaptive livelihoods as "mixed agropastoralists," but this label is misleading. Although it may be accurate from an etic technical point of view, the label "agropastoralist" belies widely divergent positions vis-à-vis adaptation strategies as understood from an emic or actor's point of view. The differences described here act as important drivers for shaping both technical and political behaviors undertaken in the gradual processes of adaptation.

Conflicts between farmers and herders over the policies and practices of land management have intensified in Mali in recent decades since the advent of democracy in the 1990s; a point on which farmers and herders widely agree. Demographic growth combines with environmental change to create a powerful driver, but the decline of national authority and decentralization of natural resource management also play substantial roles in conflict intensification. Despite increased cattle keeping, Marka agropastoralists in Madiama engage in land-use practices and political positions that favor more extensive agriculture and local political power. They favor intensification of pastoralism while maintaining relatively extensive agriculture. Fulani agropastoralists in Madiama take the opposite position, favoring intensive agriculture and taking political positions that emphasize the role of the national and regional authorities in maintenance of extensive pastoral resources. In the above example, the appeals to different levels of political authority for different objectives show that both Marka and Fulani are seeking to drive the landscape level adaptation process toward their specific goals using the political channels through which they gain the greatest leverage, emphasizing the normative nature of adaptation politics and processes.

At present, farmer-herder conflicts in central Mali are seasonally sporadic and localized, but they are driven by factors which will only continue to 
become more acute, indicating an emerging tension in the social-ecological system. Fulani aspirations and actions to maintain the prominence of extensive pastoralism occur within dynamic political and ecological contexts that are pressing against their normative cultural objectives. If these aspirations are increasingly unmet through time, as biophysical models generally suggest, we can likewise expect that Fulani cultural transformation may intensify as technical livelihood practices become more diversified. Without the development of institutional spaces to facilitate smooth and equitable changes, such forced cultural transformations have the potential to result in more turbulent social upheavals that can diminish resilience at broader systemic levels.

Put in terms of the "panarchy" concept of interactive scales of systems resilience (Gunderson and Holling 2002), such localized cultural ruptures have the potential to spread upward through "revolution," upturning social-ecological systems more broadly. The increasing threat of violent competition over diminishing natural resources has been cited as a potential outcome of climate-change pressures (Barnett and Adger 2007). Again from humanistic terms, this is clearly worth avoiding. In this sense, issues around the processes of cultural resilience and cultural transformation are especially relevant to concerns about social-ecological resilience and merit closer consideration in climate-change adaptation research.

Responses to this article can be read online at: http://www.ecologyandsociety.org/voll5/iss4/art19/ responses/

\section{Acknowledgments:}

This research was conducted as a part of the Sustainable Agriculture and Natural Resource Management program, which was funded through the United States Agency for International Development (USAID). This paper has been improved by insightful comments from two anonymous reviewers as well as Carla Roncoli, Steve Sherwood, Sarah Hunt, and Paul Richards, although the author takes all responsibility for its contents.

\section{LITERATURE CITED}

Adger, W. N., S. Dessai, M. Goulden, M. Hulme, I. Lorenzoni, D. R. Nelson, L. O. Naess, J. Wolf, and A. Wreford. 2009. Are there social limits to adaptation to climate change? Climatic Change 93:335354.

Badini, O., and L. Dioni. 2005. Landscape and soil characterization of Madiama commune. Pages 3552 in K. Moore, editor. Conflict, social capital and managing natural resources: a west African case study. CAB International, Wallingford, Oxfordshire, UK.

Ballo, A., and A. K. Ouattara. 2005. Investigation into the movements of cattle, sheep and goat herds through the Commune of Madiama. Pages 53-70 in K. Moore, editor. Conflict, social capital and managing natural resources: a west African case study. CAB International, Wallingford, Oxfordshire, UK.

Barnett, J., and W. N. Adger. 2007. Climate change, human security and violent conflict. Political Geography 26:639-655.

Basset, T. J., C. Blanc-Pamard, and J. Boutrais. 2007. Constructing locality: the terroir apprach in West Africa. Africa 77:104-129.

Batterbury, S., and A. Warren. 2001. The African Sahel 25 years after the great drought: assessing progress and moving towards new agendas and approaches. Global Environmental Change 11:1-8.

Bebbington, A. 1999. Capitals and capabilities: a framework for analyzing peasant viability, rural livelihoods and poverty. World Development 27:2021-2044.

Bell, M. A., and P. J. Lamb. 2006. Integration of weather system Variability to multidecadal regional climate change: the west African Sudan-Sahel zone, 1951-98. Journal of Climate 19:5343-5365.

Benjaminsen, T. A. 1997. Natural resource management, paradigm shifts, and the decentralization reform in Mali. Human Ecology 25:121-143.

Benjaminsen, T. A. and B. Bubacar. 2009. Farmerherder conflicts, pastoral marginalisation and corruption: a case study from the inland Niger delta of Mali. Geographical Journal 175:71-81. 
Benjaminsen, T. A., F. P. Maganga, and J. M. Abdallah. 2009. The Kilosa killings: political ecology of a farmer-herder conflict in Tanzania. Development and Change 40:423-445.

Berkes, F., and D. Jolly. 2002. Adapting to climate change: social-ecological resilience in a Canadian western Arctic community. Conservation Ecology 5: 18. [online] URL: http://www.ecologyandsociety.org/ vol5/iss 2/art18/.

Bottom, D. L., K. K. Jones, C. A. Simenstad, and C. L. Smith. 2009. Reconnecting social and ecological resilience in salmon ecosystems. Ecology and Society 14: 5. [online] URL: http://ww w.ecologyandsociety.org/vol14/iss 1/art5/.

Bruijn, M. d. and H. v. Dijk. 1994. Drought and coping strategies in Fulbe society in the Hayre (central Mali): a historical perspective. Cahiers d'études Africaines 34:85-108.

Cissé, S. 1985. Land tenure and development problems in Mali: the case of the Niger Delta. Pages 140-151 in A. Hill, editor. Population, health, and nutition in the Sahel: issues in the welfar of selected West African communities. KPI, London, UK.

Cocks, M. 2006. Biocultural diversity: moving beyond the realm of 'indigenous' and 'local' people. Human Ecology 34:185-200.

Crane, T. A. 2002. Grounded in the landscape: eliciting farmers' understanding of soil and soil fertility. Sustainable Agriculture and Natural Resource Managment Collaborative Research and Support Program, U.S. Agency for International Development (USAID), Washington, D.C., USA.

Crane, T. A. 2009. If farmers are first, do pastoralists come second? Political ecology and participation in central Mali. Pages 88-91 in I. Scoones, and J. Thompson, editors. Farmer first revisited: innovation for agricultural research and development. Practical Action Publishing, Bourton on Dunsmore, UK.

Crane, T. A. In press. Adaptation to climate change and climate variability: the importance of understanding agriculture as performance. Netherlands Journal of Agricultural Science.

Crane, T., and B. Traoré. 2005. Farmers' knowledge and perceptions of soil fertility. Pages
129-142 in K. Moore, editor. Conflict, social capital and managing natural resources: a west African case study. CAB International, Wallingford, Oxfordshire, UK.

de Boef, W., K. Amanor, K. Wellard, and A. Bebbington, editors. 1993. Cultivating knowledge: genetic diversity, farmer experimentation, and crop research. Intermediate Technology Publications, London, UK.

de Bruijn, M. 1997. The hearthhold in pastoral Fulbe society, central Mali: Social relations, milk and drought. Africa 67:625-651.

de Bruijn, M. and H. Van Dijk. 2001. Ecology and power in the periphery of Maasina: the case of the Hayre in the nineteenth century. TheJournal of African History 42:217-238.

Degnbol, T. 1996. The terroir approach to natural resource management: panacea or phantom? The Malian experience. International Development Studies Roskilde University, Roskilde, Denmark.

Dietz, A. J., R. Ruben, and J. Verhagen, editors. 2004. The impact of climate change on drylands with a focus on West Africa. Kluwer, Dordrecht, Netherlands.

Ellis, F. 1998. Household strategies and rural livelihood diversification. Journal of Development Studies 35:1-38.

Eriksen, S. H., K. Brown, and P. M. Kelly. 2005. The dynamics of vulnerability: locating coping strategies in Kenya and Tanzania. Geographical Journal 171:287-305.

Folke, C. 2006. Resilience: the emergence of a perspective for social-ecological systems analyses. Global Environmental Change 16:253-267.

Frame, B. 2008. 'Wicked,' 'messy,' and 'clumsy': long-term frameworks for sustainability. Environment and Planning C: Government and Policy 26:11131128.

Fraser, E. D. G. 2007. Travelling in antique lands: using past famines to develop an adaptability/ resilience framework to identify food systems vulnerable to climate change. Climatic Change 83:495-514. 
Gunderson, L., and C. Holling. 2002. Panarchy synopsis: understanding transformations in human and natural systems. Island Press, Washington, D. C., USA.

Harris, M. 1976. History and significance of the EMIC/ETIC distinction. Annual Review of Anthropology 5:329-350.

Jacobson, C., and A. Stephens. 2009. Crosscultural approaches to environmental research and management: a response to the dualisms inherent in western science? Journal of the Royal Society of New Zealand 39:159-162.

Jansen, K. 2009. Implicit sociology, interdisciplinarity and systems theories in agricultural science. Sociologia Ruralis 49:172-188.

Lockwood, D. 1992. Solidarity and schism: 'the problem of disorder' in Durkheimian and Marxist sociology. 2005 edition. Clarendon Press, Oxford, UK.

Maffi, L. 2005. Linguistic, cultural and biological diversity. Annual Review of Anthropology 34:599617.

Meinke, H., S. M. Howden, P. C. Struik, R. Nelson, D. Rodriguez, and S. C. Chapman. 2009. Adaptation science for agriculture and natural resource management: urgency and theoretical basis. Current Opinion in Environmental Sustainability 1:69-76.

Moore, K., editor. 2005. Conflict, social capital and managing natural resources: a west African case study. CAB International, Cambridge, Massachussets, USA.

Moritz, M. 2006. Changing contexts and dynamics of farmer-herder conflicts across West Africa. Canadian Journal of African Studies 40:1-40.

Moritz, M. 2010. Crop-livestock interactions in agricultural and pastoral systems in West Africa. Agriculture and Human Values 27:119-128.

Mortimore, M. J., and W. M. Adams. 2001. Farmer adaptation, change and "crisis" in the Sahel. Global Environmental Change 11:49-57.

Moseley, W., Julia Earl and Lassine Diarra. 2001. La décentralisation et les conflits agriculteurs- éleveurs dans le delta intérieur du Niger: quelles échelles de gestion communautaire des ressources naturelles? La gestion intégrée des ressources naturelles en zones inondables tropicales. Institut de Recherche pour le Développement (IRD), Paris, France.

Nazarea-Sandoval, V. 1995. Local knowledge and agricultural decision-making in the Philippines: class, gender and resistance. Cornell University Press, Ithica, New York, USA.

Nelson, D. R., W. N. Adger, and K. Brown. 2007. Adaptation to environmental change: contributions of a resilience framework. Annual Review of Environment and Resources 32:395-419.

Nicholson, S. 2005. On the question of the "recovery" of the rains in the West African Sahel. Journal of Arid Environments 63:615-641.

Niemeijer, D., and V. Mazzucato. 2003. Moving beyond indigenous soil taxonomies: local theories of soils for sustainable development. Geoderma 111:403-424.

O'Brien, K. 2009. Climate change and values: do changing values define the limits to successful adaptation? Pages 164-180 in W. N. Adger, I. Lorenzoni, and K. O'Brien, editors. Adapting to climate change: thresholds, values, governance. Cambridge University Press, Cambridge, UK.

Painter, T., J. Sumberg, and T. Price. 1994. Your terroir and my 'action space': implications of differentiation, mobility and diversification for the approche terroir in Sahelian West Africa. Africa 64:447-463.

Rappaport, R.. 1979. Ecology, meaning and religion. North Atlantic Books, Berkeley, California, USA.

Rhoades, R., and A. Bebbington. 1995. Farmers who experiment: an untapped resource for agricultural research and development. Pages 296307 in D. M. Warren, L. J. Slikkerveer, and D. Brokensha, editors. The cultural dimension of development: indigenous knowledge systems. Intermediate Technology Publishing, London, UK.

Richards, P. 1986. Coping with hunger: hazard and experiment in an African rice farming system. Allen and Unwin, London, UK. 
Richards, P. 1989. Agriculture as a performance. Pages 39-43 in R. Chambers, A. Pacey, and T. L. Ann, editors. Farmer first: farmer innovation and agricultural research. Intermediate Technology Publications, London, UK.

Riesman, P. 1974. Freedom in Fulani social life: an introspective ethnography. University of Chicago Press, Chicago, Illinois, USA.

Roncoli, C., T. Crane, and B. Orlove. 2009. Fielding climate change in cultural anthropology. Pages 87-115 in S. Crate, and M. Nutall, editors. Anthropology and climate change: from encounters to actions. Left Coast Press, San Francisco, California, USA.

Roncoli, C., K. T. Ingram, and P. H. Kirshen. 2001. The costs and risks of coping with drought: livelihood impacts and farmers' responses in Burkina Faso. Climate Research 19:119-132.

Scoones, I. 2009. Livelihoods perspectives and rural development. Journal of Peasant Studies 36:171196.

Scoones, I., and W. Wolmer. 2003. Introduction: livelihoods in crisis: challenges for rural development in southern Africa. IDS Bulletin 34:114.

Smucker, T. A., and B. Wisner. 2008. Changing household responses to drought in Tharaka, Kenya: vulnerability, persistence and challenge. Disasters 32:190-215.

Star, S. L., and J. R. Griesemer. 1989. Institutional ecology, 'translations' and boundary objects: amateurs and professionals in Berkeley's Museum of Vertebrate Zoology, 1907-39. Social Studies of Science 19:387-420.

Stepp, J., E. Jones, M. Pavao-Zuckerman, D. Casagrande, and R. Zarger. 2003. Remarkable properties of human ecosystems. Conservation Ecology 7(3): 11. [online] URL: http://www.ecolog yandsociety.org/vol7/iss3/art11/.

Turner, M. D. 1999. Conflict, environmental change, and social institutions in dryland Africa: limitations of the community resource management approach. Society and Natural Resources 12:643657.
Turner, M. D. 2004. Political ecology and the moral dimensions of "resource conflicts": the case of farmer-herder conflicts in the Sahel. Political Geography 23:863-889.

Turner, M. D. 2006. The micropolitics of common property management on the Maasina floodplains of central Mali. Canadian Journal of African Studies 40:41-75.

van Dijk, H., M. de Bruijn, and W. van Beek. 2004. Pathways to mitigate climate variability and climate change in Mali: the districts of Douentza and Koutiala compared. Pages 173-206 in A. J. Dietz, R. Ruben, and J. Verhagen, editors. The impact of climate change on drylands with a focus on west Africa. Kluwer, Dordrecht, Netherlands.

Vedeld, T. 2000. Village politics: heterogeneity, leadership and collective action. Journal of Development Studies 36:105-134.

Watson, A., L. Alessa, and B. Glaspell. 2003. The relationship between traditional ecological knowledge, evolving cultures, and wilderness protection in the circumpolar north. Ecology and Society 18(1): 2. [online] URL: http://www.ecologyandsociety.org/vol8/ iss1/art2/.

WinklerPrins, A. M. G.A. and J.A. Sandor. 2003. Local soil knowledge: insights, applications, and challenges. Geoderma 111:165-170.

Xu, J., E. T. Ma, D. Tashi, Y. Fu, Z. Lu, and D. Melick. 2005. Integrating sacred knowledge for conservation: cultures and landscapes in southwest China. Ecology and Society 10(2): 7. [online] URL: http://www.ecologyandsociety.org/vol10/iss2/art7/

$\dagger$ The Fulani diaspora across West Africa has been occurring for many centuries and ranges from Senegal and Mauritania in the west to Cameroon and Chad in the east. There is great diversity of experience across these regions, with each having its own particular history and current livelihood practices. As such, the discussion of Fulani here is not meant to generalize across the range of the Fulani diaspora. Although all of the Fulani represented here are from one commune, the lessons can be generalized, at most, to the Niger River Inland Delta region. 